\title{
Factors Pertaining To Rising Divorce Rate and Its Consequences on The Family Culture Of Pakistan: A Qualitative Study
}

\author{
Gulwish Khan \\ Institute of Business Management \\ Pireh Sikander \\ Institute of Business Management \\ Ather Akhlaq \\ Institute of Business Management
}

\begin{abstract}
Objective: To explore and identify factors attributing towards the rising divorce rate in Pakistan and its consequences. Materials and methods: In-depth semi structured interviews were conducted from 17 divorced participants, five out of which were males. The participants were chosen from Karachi, Lahore, Peshawar and Islamabad. Interviews were conducted via email, telephone and face-to-face meeting. Results: Findings from the interviews highlighted partner violence, sexual dysfunction, in-laws interference and temperamental incompatibility were the most common causes of divorce. Moreover, consequences of divorce included depression and loneliness, and financial and accommodation issues. It was further found that it was difficult for the divorcees to judge and trust the new person requesting marriage proposal. Another major problem found was the child custody in which usually the males have to give up their children to their mothers. Finally, it was found that children too have to go through psychological issues after their parents separate. Conclusions: Divorce is an unwanted and undesired act of termination of marriage which brings a flood of financial, social and personal issues to divorcees. Divorce has adverse consequences on both males and females such as financial crisis, psychological issues and emotional breakdown. Children suffer emotionally in the absence of either of parents.
\end{abstract}

Keywords: Divorce in Pakistan, Reasons of divorce, factors pertaining to divorce, divorce consequences

1.gulvash@gmail.com,

2. std_12258@iobm.edu.pk,

3. ather.akhlaq@iobm.edu.pk

Page | 199 
IBT Journal of Business Studies (IBT-JBS) Volume 15 Issue 2 December 2019

\section{INTRODUCTION}

Marriage, in almost every culture, is considered as a sacred bond between spouses and is a social \& legal relationship. With the increase in uncertainty in recent times, human beings yearn for strong and lasting family bonds. However, it has become increasingly difficult to steer and sustain these relationships through different weathers. When these relationships break, it has ripple effect which not only impacts the aggrieved parties but engulfs the entire society. It disrupts the process of protection and psychological satisfaction one feels (Nizamuddin, 2017).

Divorce is a stressful life event that causes symptoms of depression in both adults and children that are directly involved. (Shafer, Jensen, \& Holmes, 2016). When a man utters 'talaaq' to his wife it is called divorce. When the dissolution of marriage occurs as result of agreement between man and woman on the wish of latter, it is called 'khulah'. (Syed, 2004)

Emile Durkheim, one of the major sociologists, regarded family as 'one of the most important of social institutions'. When conjugal partners refuse to stay in this social institution due to underlying reasons, this unit is shattered which causes a chaos. It has impact on the lives of spouses as well as the offspring.

Wide literature supports that women fare worse as compared to men whereas many studies report the reverse. According to a report, men face emotional setback amongst many other consequences of divorce (Joshi, 2018). Men, comparatively, are known to have lower commitment levels which after divorce are reduced even further. Studies also report that consequences of divorce are much worse for women as compared to men even though women participation at work has increased (Brockel \& Jurgen Andreb, 2015). Divorced women are considered as social disgrace and become subject to public stigma as well as they tend to internalize self-stigma (Konstam, Karwin, Curran, Lyons, \& Celen-Demirtas, 2016). A study conducted by (Zare, Aguilar-Vafaie, \& Ahmadi, 2017) concluded that women face saddening experiences like discrimination, social labels and rejection even from their close relatives.

Unfortunately, children become collateral victims of parental divorce. Literature supports the evidence that children of divorced parents pay heavy price on different dimensions such as scoring low on tests, higher probability of dropping out of high school and low educational achievement as compared to their counter parts (Tartari, 2015). Improper handling of divorce by parents increases risk of genitourinary, gastrointestinal, dermatological and neurological issues in children(Spanish Foundation for Science and Technology FECYT, 2017). A clear correlation has been reported between child's physical morbidity and parental loss; for example; there exists a direct relationship between parental divorce and children's daily headache(Vezzetti, 2016). There are researches that support that child adverse effects of divorce will persists in long term while some researchers report contradiction. In long term, divorce drastically reduces child's competences and future earning power (Anderson, 2014) 
Divorce rates, globally, are rising at alarming rates; in Belgium it is $70 \%$ whereas in Luxembourg, Hungary, Portugal and the Czech Republic it is 60\% (Ramzan, Akhtar, Ahmad, Zafar, \& Yousaf, 2018). Divorce and khula trend has been observed in Pakistan as well.In Punjab, 16,942 khula cases were registered in 2014 that rose to 18,901 cases in 2016 (Ramzan, Akhtar, Ahmad, Zafar, \& Yousaf, 2018). A report stated that in 2017, 15,000 and 6,000 khula cases were registered in two biggest cities of Pakistan - Karachi and Lahore, respectively (Ferozi, 2017).

Since divorce rate has been rising in Pakistan and a number of issues are developing as its consequences, therefore, it is important to explore the factors responsible for dissolution of marriage. This study will help to identify the key factors behind divorce and its consequences and also the ways to curb it as much as possible.

\section{METHODS}

\section{Design}

An in-depth semi structured interview topic guide was prepared.. The participants were asked several questions related to reasons of divorce, problems faced right after separation and the aftermath in context of personal and children sufferings.

\section{Sampling and Recruitment}

Purposive sampling method was used in our research which led to snowball sampling during the entire process. Purposive sampling is a non-random sampling technique where the participants are chosen on the basis of researcher's judgement to be the best suited candidate.

(Etikan, Musa, \& Alkassim , 2016). According to Biernacki \& Waldorf (1981) snowball sampling or chain referral sampling refers to the technique where researchers get reference of further respondents from participants who think the referal would be appropriate and relevant to a specific study. The divorced males and females were identified through Facebook groups and other sources of social circle as well. During the interviews, some respondents gave leads to other divorcees who actively participated in our research project. We stopped approaching more respondents when reached at the point of data saturation. Data saturation occurs when sufficient data is collected that is enough to replicate the study and no new codes are generated from further information gathering. ( Fusch \& Ness, 2015)

\section{Data Generation}

Invitations for interview were sent to 25 people but we got response from 20 out of which 17 actually gave their interview. We approached the target audience located in four major cities of Pakistan, namely, Karachi, Lahore, Islamabad and Peshawar. Four respondents gave us interview in person at Karachi while eight responded via email and rest of five gave interview over the call from other cities of Pakistan (See Table 1 in Appendix). Each interview lasted between 20 minutes to 40 minutes.

\section{Data Handling and Analysis}

Data received through various means was saved and transcribed carefully. Field notes and observations were prepared while data gathering. We used thematic Page $\mid 201$ 
analysis to reach at the results and extra care was taken to keep the analysis researcher unbiased. Thematic analysis is a qualitative analysis technique in which themes are drawn from respondents' answers and further sub themes are developed emerging from major themes. (Braun \& Clarke, 2006)We tried to be neutral and interpreted data from interviewees' perspective keeping in view their verbal and nonverbal gestures during communication.

\section{RESULTS}

As a result of our thematic analysis, two major themes were generated which were followed by subthemes under each: 1 - factors contributing towards dissolution of marriage; 2- post divorce consequences and their effects on divorcees and society (See Image 1 in appendix).

\section{Factors Contribute Towards Divorce}

\section{Intimate Partner Violence}

There are several factors which compel the partners to separate from each other forever. Intimate partner violence is one of the major reasons which lead to such extreme step by the counter partner. In this research five respondents unfolded that they were constantly abused physically and verbally by calling names and taunts. According to research conducted by Rosenbaum \& O'Leary (1981) on group of abusive and non-abusive marriages, the abusive group scored lowest in marital satisfaction.

My ex used to abuse me physically and torture me mentally. He was a psycho patient. I remember he used to torture me in different ways like burning my skin with cigarette and hot iron. The worst he did was rub red pepper on sensitive parts of my body. I can never forget the pain I bore in those times. It was a nightmare. (R 13)

Mental and physical abuse was the prime reasons I decided to quit this toxic relationship and I am quite satisfied now. (R I)

\section{Sexual Dysfunction}

Sexual dysfunction is another common reason for dissolution of marriage from both the genders. In our research women participants revealed that their ex-husbands were either gays or impotent and this reality was concealed prior to marriage.

My husband was very shy and not interested in getting physical. (R11)

On the contrary two of the male respondents disclosed that their wives lacked sexual desire and thus resultantly their physical and emotional bond weakened over the years.

...she was not modern or seductive. She was least interested to become physical and wanted to quit as soon as we started. I used to be so frustrated and it was badly affecting my work life as well as my ego. (R 7) 


\section{In-Laws Interference}

Third major factor leading to termination of wedlock highlighted in our research is the in-laws trouble. Unnecessary interference and undesired involvement of in-laws create conflicts between the couples who end up into parting from each other. The female respondents stated that their in-laws' interference into petty issues created big troubles in their marital relationship and eventually it resulted in misunderstandings between the couples.

My ex mother in law had only one son, she got so jealous, she was not able to share him with me. (R4)

Unwanted family involvement from both sides directed the situations to a path which led to misunderstandings and eventually we got separated. I still miss her, she was a nice girl though. (R5)

\section{Temperamental Incompatibility}

Another important cause of divorce in Pakistan is the existence of temperamental incompatibility where both the couples have different interests, perspective of life and beliefs. There is no harmony in their living style and mental compatibility.

Mental incompatibility was the main reason of separation. He insulted me all the time and was jealous of my success as I had my own identity my own business. (R12)

We were two opposite poles of the globe. He had own ideas and was very dominant. I remember he always called me ignorant and illiterate who couldn't reach at his level of thinking. (R5)

\section{Extra Marital Affair}

In our findings one more reason was identified as a factor of divorce which is extra marital affair. People who cheat on their spouses are unable to develop a healthy and happy relationship between each other. In our society cheating on spouses is considered an unforgettable and unforgivable act which makes this relationship a burden on each other.

She took divorce forcefully. She had an affair with her colleague. (R17)

My ex-husband was involved in another girl who forced him to divorce me. They were involved for last six months and I was completely unaware of all this. I found his explicit conversation on mobile and I confronted. My ex had already lost interest in me and he finally chose another woman. (R8)

\section{Post-Divorce Consequences on the Family Culture of Pakistan}

Divorce is a traumatic process which comes along a series of problems and issues afterwards. In our research some of the common consequences were unfolded after divorce which included financial crisis, psychological problems and children issues. 
The foremost issue which immediately arises after dissolution of marriage is the financial crisis as there is lack of family support especially in case of females. 7 out of 11 female participants stated that they did not get any financial and moral support from their families. They were considered as a burden on them and some of their families suggested patch-up the broken marriage. We also found out that majority of female respondents were completely financially dependent on their husbands and after divorce the biggest challenge for them was to stand on their own feet and feed themselves and their children independently.

No I had no support at all, I had to immediately stand on my own feet, they (family) tried to take fatwas and make arrangements that somehow the in laws accepted me and took me back. (R2)

I didn't get any emotional help but reluctantly they kept me in their house. I had financial problem in raising my kid. (R15)

I had to face deadly taunts from my family. Financial issues were there as I was not much educated. (R8)

My family didn't accept me back. They created hurdles and tried hard for patch up but I insisted on khulah and finally took it. I faced financial problem too as I wasn't earning. (RII)

On the other hand, male respondents revealed that they were financially sound and self-dependent so did not face any financial crisis. They also told that they got emotional support from their families.

I was financially self-dependent. My family emotionally supported me and kept me composed. (R7)

Yes, my brother got me a new job as I was jobless at that time and my father supported me financially for a few months. (R5)

It is evident from our findings that females get less financial and emotional support from their families after the termination of marriage, however, most of the males get enough financial and moral support from their families.

Psychological issues are another aftermath of divorce. The divorcees go through number of emotional problems such as depression, anxiety, loneliness and mistrust. During the interviews, the respondents revealed that they were facing severe depression and anxiety right after separation. They described their feelings as sadness and gloom had engulfed them and they were giving up on normal life.

I got into depression, insomniac and emotionally felt devastated. (R3)

I was going through emotional break down. I had panic attacks and I was distressed all the time. It took years to come out to normal 
routine and life. ( $R 9)$

Loneliness is the second major psychological issue which arises after the dissolution of marriage. The couples who spend some time together develop an emotional bond and attachment with each other and complete termination of marriage makes them lonely and emotionally weak.

Yes, I think divorce changes a person for no good. It breaks you. It puts never healing scars on soul. It gives you loneliness and mistrust. (R13)

Loneliness was killing me after divorce especially when I used to see happy couples around. I started dating multiple girls to end my loneliness but I couldn't forget her. (R7)

I feel better to come out of abusive relationship but I feel lonely at times while seeing older couples together. (R6)

In our findings another common psychological issue was mistrust. The divorced males and females lose trust in opposite genders. They see other individuals from the same prism and hardly trust others for remarriage or emotional bondage again.

It was a dark phase in my life. He shattered my trust so badly that I cannot trust anyone for marriage or I feel nobody can understand me. Loneliness depresses me a lot. I have changed as I don't open up to others now. (R9)

....I have trust issue on other females. I feel all women are alike and I won't be able to trust them for good once again. (R7)

Social stigmatization is another consequence of divorce which affects women more than men in our society. Divorced women are perceived as the problem creator and their family disowns them for being wrong regardless of anyone's fault.

I took khulah and my ex did every possible threat and act to stop us from going into courts. People doubted my character even my own brother threw pebbles on me in the form of false allegations. (R10)

...they blamed me to be barren and cannot bear children so I was divorced. It was merely a lie. Nobody in my family was ready to marry me. They thought I was actually barren and I was not invited to baby shower events of my relatives. ( $R 2)$

Children suffer the most when their parents get separated from each other forever. Divorce has an adverse effect on the personality of children who find this situation very depressing and frustrating. Our findings reveal that children feel absence of either of the parents as they live with the custodian most of the time. Moreover, their academic performance is badly affected due to emotional turmoil. We also Page | 205 
found out that in Pakistan people do not prefer broken families for marriages and children of divorced parents struggle to find a good proposal for themselves.

I miss my 2 year old kid as he is with mother. My kid suffered. Things could be resolved with time. It was a bad decision. (R13)

My daughter missed her father. She was emotionally so attached so making her understand was a challenge for me as she as only 5 that time. (R12)

I feel social pressure. I regret only that my children suffer because of proposals. I spent two decades with my ex-husband and children were grown up. I faced problems in children's proposals as people do not like to be tie knot with broken families. (R6)

My daughter often asks me why I don't have daddy when my friends have. It breaks me. She was a brilliant student but now I often get complaints from her teacher that she has lost focus and most of the time she is sitting with blank face. She is just 8 years old. (R15)

\section{DISCUSSION}

\section{Overview of Findings}

In Pakistan, dissolution of marriage is just the beginning and with it come a lot of associated costs. Results indicated that relatively men had better financial and emotional support than women after the divorce. According to 'Global Gender Gap Index 2018', Pakistan scored 148 of 149 countries in terms of gender parity across four areas: education, heath, economic opportunity and political empowerment. Woman, in Pakistani culture is assumed to look after the house whereas man is the bread-winner. So, after the divorce, woman becomes dependent on her family that often refuses to support her as supported by findings of this study. Consequently, she has to become financially stable but due to gender parity, woman has to outperform and undermine the male breadwinner ideal.

Another major cost associated with divorce is health. According to the data, divorce obstructed woman's health in terms of insomnia, depression, anxiety and panic attacks. In contrast, man suffered psychologically because of the absence and longingness of their children. Distrust and loneliness were qually felt by man and women both.

\section{Strengths and Limitations}

Most of the researches conducted in Pakistanstudy the divorce from the women perspective. This study, however, gathered data from both the parties involved in divorce - man and woman. Maximum variation sampling was used to recruit respondents for this research and interviews were conducted until the data saturation was reached. Participants were also given the opportunity to add their views in case something was missed during the interview. Researchers also gave attention to non-verbal ques and observed the moments when the participants were uneasy in 
answering since divorce is a very personal and traumatized incident.

However, not all participants who were approached gave response. Furthermore, due to busy schedule of some participants, few interviews were conducted via mobile/landline or Skype and some participants requested to respond to questions in writing i.e. via email. Divorce is considered unmentionable event therefore it seemed difficult for respondents to share their experiences, but participants were given assurance of confidentiality and we believe the shared information depicts the true picture of contributors and consequences of divorce.

\section{Considering the Findings in the Light of Existing Literature}

Findings of this research are consistent with the existing literature. Quality of marital life effects the probability of divorce (Qadir, de Silva, Prince, \& Khan, 2005). A study conducted to identify sources of marital dissatisfaction reported 12 complaints from the spouses that contributed to dissatisfaction namely - neglect of home or children, financial problems, physical and verbal abuse, infidelity, sexual incompatibility, drinking, in-law trouble, lack of love and excessive demands (Levinger, 1966). Consequences associated with marital dissatisfaction are feeling of loneliness, depressive symptoms in spouses and eventually leading to a divorce(Doohan, Carrère, \& Riggs, 2010).

According to our Islamic doctrines, Islam emphasizes on preserving family at all cost (Ramzan, Akhtar, Ahmad, Zafar, \& Yousaf, 2018) however, in Pakistan, rise in divorce rate is evident (Nizamuddin, 2017). On Hofstede's model of assessing national cultures, Pakistan is highly collectivist-oriented country (Islam, 2004) that means people share strong connection with their families and they take responsibility for one another. Data gathered depicted that interference from couple's family was one of the most iterated contributor towards divorce which is prevalent due to collectivism in Pakistan's culture. A study (Ayub \& Iqbal, 2012) concluded that in Pakistan in-laws relationship for males as well as female is momentous for marital satisfaction. Prevalence of other contributors, as identified in the data gathered, intensify the situation that led to dissolution of marriage. Other contributors are physical and verbal abuse, incompatibility and sexual dysfunction. Presence of these factors influence marital satisfaction in couples.

\section{Recommendation to Curb Rising Divorce Rate In Pakistan}

Keeping in view our research work, we suggest some of the ways to strengthen marriage and curb rising divorce rate in Pakistan:

1. There should be established marriage counseling institutes by government and private organizations which can help the couples cope up with their psychological problems and resolve conflicts between each other peacefully.

2. The government should make divorce laws stricter to control divorce on petty issues which could be resolved without taking such severe step of marriage termination.

3. A complete chapter on marriage should be part of curriculum at intermediate level where students are apprised of Islamic rules about marriage and rights and responsibilities of spouses. This will help them become role models in a successful marriage. 
4. The families where conflict arises because of financial crisis, women can contribute towards income through online work from home. The private and government organizations can provide such online work opportunities to women in Pakistan. It will encourage women to earn money besides home making.

5. The in-laws should avoid interference into couple's matters which can lead to misunderstanding initially and separation eventually.

\section{CONCLUSION}

Divorce is an unpleasant act in the eyes of society and Islam. It has a negative impact on a number of people associated with that marriage which directly affects the couples and severely the children. Most common factors pertaining to rising divorce rate in Pakistan are intimate partner abuse, sexual dysfunction, in-laws interference and mental incompatibility between the couples. Divorce comes with an after math of financial crisis, several psychological issues, and social issues and children problems. Children suffer a lot as a result of marriage dissolution; therefore, it should be avoided as much as possible to run a family system smoothly in accordance to Islamic teachings.

\section{Competing Interests}

There was no conflict of interest in this research project.

\section{REFERENCES}

Fusch, P. I., \& Ness, L. R. (2015). Are We There Yet? Data Saturation in Qualitative Research. The Qualitative Report.

Anderson, J. (2014). The impact of family structure on the health of children: Effect of divorce. The Linacre Quaterly, 81(4), 378-387. doi:10.1179/002436391 4Z.00000000087

Ayub, N., \& Iqbal, S. (2012). The factors predicting marital satisfaction: A gender difference in Pakistan. International Journal of Interdisciplinary Social Sciences, 6(7), 63-11.

Biernacki, P., \& Waldorf, D. (1981). Snowball Sampling: Problems and Techniques of Chain Referral Sampling.

Braun, V., \& Clarke, V. (2006). Using Thematic Analysis in Psychology. Qualitative Research in Psychology.

Brockel, M., \& Jurgen Andreb, H. (2015). The Economic Consequences of Divorce in Germany: What Has Changed since the Turn of the Millennium. Comparative Population Studies, 277-312. doi: http://dx.doi.org/10.12765/CPoS-2015-04en

Doohan, E.-A. M., Carrère, S., \& Riggs, M. L. (2010). Using relational stories to predict the trajectory toward marital dissolution: The oral history interview and spousal feelings of flooding, loneliness, and depression. Journal of Family Communication, 10(1), 57-77.

Etikan, I., Musa, S. A., \& Alkassim , S. R. (2016). Comparison of Convenience Sampling and Purposive Sampling. American Journal of Theoretical and Applied Statistics.

Ferozi, M. (2017). Social Media Blamed for Rise in Divorce Cases. Retrieved from https://dailytimes.com.pk/136638/social-media-blamed-rise-divorce-cases/ 
Islam, N. (2004). Sifarish, sycophants, power and collectivism: Administrative culture in Pakistan. International Review of Administrative Sciences, 70(2), 311-330. doi:https://doi.org/10.1177/0020852304044259

Joshi, N. (2018). Effects of Divorce on Men. Retrieved from https://menwit.com/ effects-of-divorce-on-men

Konstam, V., Karwin, S., Curran, T., Lyons, M., \& Celen-Demirtas, S. (2016). Stigma and divorce: A relevant lens for emerging and young adult women? Journal of Divorce \& Remarriage, 173-194. doi:https://doi.org/10.1080/10502 556.2016.1150149

Levinger, G. (1966). Sources for marital dissatisfaction among applicants for divorce. American Journal of Orthopsychiatry, 35(5), 803-807. doi:Levinger, G. (1966). Sources of marital dissatisfaction among applicants for10.1111/j.1939-0025.1966.tb02407.x

Nizamuddin, M. (2017, January 26). Rising Divorce Rates in Pakistan - Its Impact on the individual and Society. Retrieved from http://blogs.jpmsonline. $\operatorname{com} / 2017 / 01 / 26 /$ rising-divorce-rates-in-pakistan-its-impact-on-theindividual-and-society/

Qadir, F., de Silva, P., Prince, M., \& Khan, M. (2005). Marital satisfaction in Pakistan: A pilot investigation. Sexual and Relationship Therapy, 20(2), 195209. doi:https://doi.org/10.1080/14681990500113260

Ramzan, S., Akhtar, S., Ahmad, S., Zafar, M. U., \& Yousaf, H. (2018). Divorce Status and Its Major Reasons in Pakistan. Sociology and Anthropology, 6(4), 386-391. doi:10.13189/sa.2018.06040

Rosenbaum, A., \& O'Leary, K. D. (1981). Marital Violence: Characteristics of Abusive Couples. Journal of Consulting and Clinical Psychology.

Shafer, K., M. Jensen, T., \& Holmes, E. (2016). DIvorce Stress, Stepfamily Stress, and Depression among Emerging Adult Stepchildren. Journal of Child and Family Studies, 3(26), 851-862. doi:10.1007/s10826-016-0617-0

Spanish Foundation for Science and Technology FECYT. (2017). Parents' divorce increases risk of health disorders in children. Retrieved from https:// medicalxpress.com/news/2017-05-parents-divorce-health-disorders-children. html

Syed, M. A. (2004). The position of women in Islam- A preogressive view. New York: State University of New York Press, Albany.

Tartari, M. (2015). Divorce and the cognitive achievement of children. International Economic Review, 56(2), 597-645. doi:10.1111/iere.12116

Technology, S. F. (n.d.).

Vezzetti, V. (2016). New approaches to divorce with children: A problem of public health. Health Psychology Open, 3(2). doi:https://doi. org/10.1177/2055102916678105

Vrouvas, M. (n.d.). The Effects of Divorce on Soceity. Retrieved from https://info. legalzoom.com/effects-divorce-society-20105.html

Zare, S., Aguilar-Vafaie, M. E., \& Ahmadi, F. (2017). Perception of Identity Threat as the Main Disturbance of Iranian Divorced Women: A Qualitative Study. Journal of Divorce and Remarraige, 58(1). doi:https://doi.org/10.1080/10502 556.2016 .1257902 


\section{APPENDIX}

Topic Guide

Total years of marriage

Post divorce period

What were the factors which attributed towards this step?

What were the problems that you faced immediately after divorce?

Did you get sufficient financial and emotional support from your family after all this happened?

Do you think that your relationship with your children improved or suffered as a result of your divorce?

Do you feel regrets for the impact of your divorce on you and children?

Table 1

\begin{tabular}{|l|l|l|}
\hline No. of Respondents & Medium of Interview & Cities \\
\hline 4 & In-Person & Karachi \\
\hline 6 & E-mail & Lahore \\
\hline 2 & E-mail & Islamabad \\
\hline 3 & Phone & Peshawar \\
\hline 2 & Phone & Islamabad \\
\hline
\end{tabular}

Image 1

Main Themes Emerged from the Research

1-Factors contributing towards divorce

- $\quad$ Physical \& verbal abuse

- Sexual dysfunction

- In-law interference

- Temperamental Incompatibility

2-Post-Divorce Consequences

- Financial Crisis

- $\quad$ Psychological issues

- Social stigmatization

- Children issues 